Examining the Relationship Between Social Media Characteristics and Psychological Dispositions

\author{
Corresponding Author: \\ Professor Debra Grace \\ Department of Marketing \\ Griffith Business School \\ Griffith University \\ Southport, Qld \\ Australia \\ Email: d.grace@griffith.edu.au \\ Phone: 617-55528027 \\ Fax: 617-55528085 \\ Dr Mitchell Ross \\ Department of Marketing \\ Griffith Business School \\ Griffith University \\ Southport, Qld \\ Australia \\ Email:m.ross@griffith.edu.au \\ Phone: 617-55528269 \\ Fax: 617-55528085 \\ Dr Wei Shao \\ Department of Marketing \\ Griffith Business School \\ Griffith University \\ Southport, Qld \\ Australia \\ Email: w.shao@griffith.edu.au \\ Phone: 617-55529292 \\ Fax: 617-55528085
}

KEYWORDS: Personality, psychological dispositions, consumer behavior, media, advertising, behavioral intentions, social media. 


\title{
Examining the Relationship Between Social Media Characteristics and Psychological Dispositions
}

\begin{abstract}
Purpose: This study adopts a novel approach to the study of individuals' psychological dispositions that predict Facebook usage/non-usage. Given the historically disappointing results associated with studies that treat personality traits/dispositions as enduring and invariant, contemporary thought accepts that it is the interaction between dispositions and situations that influence behavior. In this study the situation (in this case, Facebook) is positioned as the antecedent stimulus for the activation of context-relevant psychological dispositions that, subsequently, facilitate behavioral prediction (i.e. Facebook usage/nonusage). Moreover, Facebook (the stimulus) is examined through its perceived psychological, rather than normative, features in order to identify context-relevant dispositions.
\end{abstract}

Design/Methodology: This two-study project adopts a research framework developed through the integration of communication theories (such as, uses and gratifications theory; media systems dependency theory) and psychological processing theories (such as, cognitive-affective personality theory and stimulus-organism-response theory).

Findings: The findings of Study 1 (involving data collected from 523 users/non-users of Facebook) lead to the identification of the perceived psychological features of Facebook which are categorised under the umbrella terms of (1) interaction, (2) self-image control, (3) usage volition, and (3) risk. Using these features (identified in Study 1) to guide in the selection of context-relevant dispositions, rather than arbitrarily selecting dispositions, the hypotheses for Study 2 are developed. As a result, Study 2 involves the discriminant 
analysis of data gathered from 579 user/non-users of Facebook to determine if contextrelevant psychological dispositions (such as sociability, shyness, self-disclosure, susceptibility to interpersonal influence and concern for privacy) accurately predict behavior of both users and non-users of Facebook.

Originality/Value: The findings provide a psychological road-map for Facebook advertisers (and marketers, in general), which can be used to develop and test media-specific advertising strategy. Furthermore, a significant contribution of this study resides within the research approach itself (refer Figures 1 and 2) which can be used to guide, not only media research, but also other marketing and business research that is characterized by context specificity. 


\section{Examining the Relationship Between Social Media Characteristics and Psychological Dispositions}

\section{ABSTRACT}

Purpose: This study adopts a novel approach to the study of individuals' psychological dispositions that predict Facebook usage/non-usage. Given the historically disappointing results associated with studies that treat personality traits/dispositions as enduring and invariant, contemporary thought accepts that it is the interaction between dispositions and situations that influence behaviour. In this study the situation (in this case, Facebook) is positioned as the antecedent stimulus for the activation of context-relevant psychological dispositions that, subsequently, facilitate behavioural prediction (i.e. Facebook usage/nonusage). Moreover, Facebook (the stimulus) is examined through its perceived psychological, rather than normative, features in order to identify context-relevant dispositions.

Design/Methodology: This two-study project adopts a research framework developed through the integration of communication theories and theoretical frameworks (such as, uses and gratifications; media systems dependency theory) and psychological processing theories (such as, cognitive-affective personality theory and stimulus-organism-response theory). Study 1 adopted a qualitative approach to determine the psychological features of Facebook, as perceived form the individual's standpoint. Study 2 involved a national on-line survey, developed from the findings from Study 1, to explore context-relevant psychological dispositions in their prediction of Facebook behaviour. 
Findings: The findings of Study 1 (involving data collected from 523 users/non-users of Facebook) lead to the identification of the perceived psychological features of Facebook which are categorised under the umbrella terms of (1) interaction, (2) self-image control, (3) usage volition, and (3) risk. Using these features (identified in Study 1) to guide in the selection of context-relevant dispositions, rather than arbitrarily selecting dispositions, the hypotheses for Study 2 are developed. As a result, Study 2 involves the discriminant analysis of data gathered from 579 user/non-users of Facebook to determine if contextrelevant psychological dispositions (such as sociability, shyness, self-disclosure, susceptibility to interpersonal influence and concern for privacy) accurately predict behaviour of both users and non-users of Facebook.

Originality/Value: The findings provide a psychological road-map for Facebook advertisers (and marketers, in general), which can be used to develop and test media-specific advertising strategy. Furthermore, a significant contribution of this study resides within the research approach itself (refer Figures 1 and 2) which can be used to guide, not only media research, but also other marketing and business research that is characterized by context specificity. 


\section{INTRODUCTION}

Social media is no longer in its infancy with social networking sites becoming the most prevalent online activity in the world. In fact, predictions reveal that nearly one in three people, worldwide, will use these networks by 2017 (eMarketer, 2013). Within the realms of social media, Facebook is the highest trafficked website in the world (Alexa, 2013) with more than one billion users (Vance, 2012), thus, creating enormous opportunities for marketing practitioners. However, in capitalizing on these opportunities, marketers face new challenges as they learn to adapt to the needs of the modern interactive consumer.

The linear model of communication (i.e. source, message, recipient), which has traditionally been used to describe advertising, has long been criticized for its inability to accommodate an understanding of communicative intercourses (Stern, 1994). This limitation is particularly relevant in today's digital marketplace, whereby the exponential usage growth of social media sites has drastically modified how marketers and consumers communicate (Paul, 1996; Lagrosen, 2005; Rapp et al., 2013). While the advent of social media represents the cause of this dramatic shift in marketing communications, the psychological and behavioural effect of modern media on its participants has not been given significant recognition.

Downplaying the role of media as being a marketing communications' facilitator may have been historically valid; however, contemporary thought needs to acknowledge that media is a causal (or an antecedent) stimulus which activates the context-relevant psychological dispositions (of an individual) upon which the behavioural response is formed. In adopting this view, this study focusses on the psychological features of a social networking site, 
Facebook, in the activation of context-relevant psychological dispositions that, ultimately, predict individuals' Facebook (non) usage. In order to do this, this study draws on communication theories and theoretical frameworks (such as, uses and gratifications; media systems dependency theory) and psychological processing theories (such as, cognitiveaffective personality theory and stimulus-organism-response theory) to provide an innovative research framework for this two-part study.

Specifically, the goal of this research is to determine the psychological dispositions that provide predictive power in terms of Facebook usage. We take the view that Facebook is the stimulus and we allow the consumer-perceived characteristics of Facebook to drive the identification of relevant psychological constructs (i.e. organisms) that predict behavioural response (i.e. Facebook usage and non-usage). In doing so, we provide a psychological roadmap for Facebook advertisers (and marketers, in general), which can be used to develop and test media-specific advertising strategy. Furthermore, a significant contribution of this study resides within the research approach itself (refer Figures 1 and 2), which can be used to guide not only media research, but also other marketing and business research that is characterized by context specificity.

\section{THEORETICAL FRAMEWORK}

Stimulus-organism-response (SOR) theory has long been used to understand consumer behaviour (Andreason, 1965; Bettman, 1979; Hoyer \& Maclnnis, 1997). The most modern conceptualization of this theory was proposed by Jacoby in 2002 , who did not criticise the 
intellectual content of the original theory, but rather the linearity of the model, proposing that the model should be depicted from a more "three-dimensional" perspective (Jacoby, 2002). This notion is based on the argument that the three key components (stimulus, organism, response) are not mutually exclusive, in that one object can represent stimuli in one instance, while representing an organism or response in another instance. For the purposes of this research this view is adopted, resulting in the argument for Facebook (i.e. media) as being the stimulus, psychological dispositions as residing in the organismic component, and Facebook usage (non-usage) as being the response. Using SOR as the basic theoretical foundation for this study, the ensuing sections explain how the integration of cognitive-affective system theory of personality (Mischel \& Shoda, 1995) uses and gratifications (Blumler \& Katz, 1974) and media dependency theory (Ball-Rokeach \& DeFleur, 1976), facilitate a higher-order theoretical framework which, not only guides this study, but can be used to inform future context-specific research (refer Figure 1).

\section{Cognitive-Affective System Theory of Personality}

Traditionally, an individual's personality traits were purported to be stable predictors of behaviour, which were invariant across situations (Michel \& Shoda, 1995). Decades of research, producing disappointing results based on this hypothesis (e.g., Newcomb, 1929; Vernon, 1964; Mischel, 1968; Mischel \& Peak, 1982), led to a more interactive view of behavioural prediction, resulting in numerous studies finding that interaction effects between traits and situations explained more variance in behaviour (e.g., Endler \& Hunt, 1969; Kulik, Oldham \& Hackman, 1987; Edwards, 1991; Nijssen, Singh, \& Sirdeshmukh, 2003; Dabholkar \& Bagozzi, 2002). However, this has led to the challenge of trying to determine 
which personality traits are relevant in which situations. In meeting this challenge, Mischel and Shoda (1995) warn that "if situation units are defined in terms of features salient for the researcher but trivial for, or irrelevant to, the individuals studied, one cannot expect their behaviours to vary meaningfully across them" (p. 250). Ross et al. (2009), by their own admission, fell victim to this very situation in their study of personality and motivations associated with Facebook use. Their disappointing findings in relation to personality (defined by the Five-factor approach) led them to conclude that "motivational factors......may be more useful in understanding Facebook use than the ones we selected" (Ross et al., 2009, p. 582).

In order to "reconcile the paradoxical findings on the invariance of personality and the variability of behaviour across situations" (p. 246), Mischel and Shoda (1995) proposed a cognitive-affective system theory of personality which re-conceptualized situations, dispositions, dynamics and invariance in personality structure. Firstly, they view personality in terms of "behavioural dispositions or traits that predispose individuals to engage in relevant behaviours" (p. 246). They argue that if, for example, a person has a conscientious disposition, the more they will engage in conscientious behaviour. Secondly, while their theory assumes that personality dispositions are enduring, the degree to which they are activated (i.e. have influence in any given context) differ across situations. However, they argue that individuals do not passively react to the subtle or normative characteristics of the situation; rather, individuals are active and goal-directed and, in part, create the situations themselves based on these motivations (Mischel \& Shoda, 1995). In other words, 
"if situations are redefined to capture their basic psychological features, then information about a person's behaviour tendencies specific to these situations (Kelly, 1955; Mischel, 1973) might be used to predict behaviour across a broad range of contexts that contain the same psychological features (Shoda et al., 1994)" (Mischel \& Soda, 1974; p. 248)

Integrating cognitive-affective personality theory with SOR theory, this paper argues that the stimulus, relating to any given context/situation, should be viewed from a psychological characteristics perspective; organisms refer to the individual's psychological dispositions that are activated by the stimulus; and responses are behaviourally-articulated in accordance with the relevant psychological dispositions. In drawing on this generic theory, the ensuing section outlines the "stimulus" pertinent to this study.

\section{Facebook as Stimulus}

Stimulus factors refer "to the environment as encountered by the individual" (Jacoby 2002, p. 54). For the purposes of this study, as Facebook is the environment under investigation, Facebook is positioned (within our conceptual model) as representing the "package of stimuli", influencing psychological trait activation and the individual's related behavioural response. However, in contrast to past research (e.g. Wendel \& Dellaert, 2005), it is not the explicit, static or obvious features (stimulus) of Facebook that will inform the model; it is the psychological features that represent the key focus. In order to understand the psychological stimuli associated with Facebook, this paper draws on the theories of uses and gratification (Blumler and Katz 1974) and media dependency theory (Ball-Rokeach \& 
DeFleur, 1976), which have proven to be valid theoretical models, appropriate for application in the social media context.

Although originating in the 1970s (Blumler \& Katz 1974), in more recent times, uses and gratifications has been widely used as the theoretical framework for Internet research (e.g., Ruggiero, 2000; Hollenbaugh \& Ferris, 2014; Masur et al., 2014). Based on the notion that individuals are motivated to engage with media in order to satisfy self-perceived needs, the theory assumes that the audience is "active"; the audience exercises choice in relation to media that will fulfil their needs; and the media competes with other sources of need satisfaction (Katz, Blumler \& Gurevitch, 1974). Media dependency theory (Ball-Rokeach \& DeFleur, 1976) extends this theory by promoting that individuals seek out media for goal (rather than need) gratification and highlight that the more an individual uses the media for goal gratification, the more dependent they become on the media. DeFleur and BallRokeach (1989) go further to categorise goal motivations to include social and selfunderstanding; interaction and action orientation; and social and solitary play; all of which hold significant relevance to interactive media and, in particular, social media.

On the basis of the preceding discussion, in this study, Facebook "stimuli" is examined from the perspective of the individual's psychological uses, needs and goals. This approach is particularly valid as uses and gratifications researchers argue that "methodologically speaking, many of the goals of mass media use can be derived from data supplied by individual audience members i.e. people are sufficiently self-aware to be able to report their interests and motives in particular cases" (Katz et al., 1974, p. 17). In understanding the goals and needs of individuals, being met by the media (i.e. Facebook), the relevant 
psychological traits that will be activated in the organism-response process can be more accurately determined.

\section{Organism-Response Process}

According to SOR theory, organismic factors are said to reside "in the realm where we subconsciously process incoming stimuli, internally activating stimuli, or both" (Jacoby 2002, p. 54). This subconscious space is where an individual's dispositional traits are stored, and subsequently activated. However, it is the stimuli (psychological features of the situation) that are ultimately responsible for which dispositional traits are activated or, alternatively, remain inactive (in other words, which dispositions bear no context-relevance).

From a behavioural perspective, cognitive-effective personality theory (Mischel \& Shoda, 1995) clearly demonstrates the close link between the stimuli-activated personality disposition and behaviour (often referring to these dispositions as behavioural dispositions). However, the authors suggest that merely establishing a relationship between the stimulus, psychological dispositions and an individual's engagement with a behaviour may create a somewhat false sense of reality. The only way to examine the psychological features of Facebook (and the subsequent personality dispositions that truly predict behaviour), is to measure those individuals who do engage in the behaviour and those individuals who do not engage in the behaviour. In adopting this approach, the variables are identified that are strong enough to discriminate between behavioural engagers and non-engagers, thus, providing predictive power across all individuals in relation to the stimuli (i.e. Facebook). 


\section{Conceptual Framework}

In summarizing the previous sections, which cover various theoretical and conceptual perspectives, we provide the following summary, also graphically depicted in Figure 1. Using S-O-R theory as the overarching theoretical framework for this paper, we develop a contextspecific conceptualization, which represents a unique approach to understanding and predicting Facebook (non) usage. Figure 1 depicts the development of this approach in line with Jacoby's (2002) theory by showing the context-specific conceptualization across the SO-R components i.e. stimulus, organism and response. As such, these are further summarized.

Stimulus: As previously discussed, the stimulus is the environment (in this case, Facebook) as encountered by the individual (Jacoby, 2002). The individual encounters, or interacts with media to satisfy self-perceived needs and seek out goal gratification (i.e. uses and gratification/media dependency theory) therefore the stimulus (i.e. Facebook) should be examined from a uses and gratification perspective (see Figure 1).

Organism: The organism represents the sub-conscious processing of incoming and internally- activated stimuli (Jacoby, 2002), which involves the activation of the individual's personality/behavioural dispositions (i.e. cognitive-effective personality theory). Contextspecifically, the organism is represented by the individual's personality/behavioural dispositions that are subsequently activated by Facebook goal (non) attainment (i.e. the stimulus) (refer Figure 1). 
Response: According to Mischel and Soda, 1974), if the situation (i.e. stimulus/Facebook) is defined by its basic psychological features then individuals' behavioural tendencies (i.e. personality/behavioural dispositions) can be identified within that situation and used to predict behaviour (i.e. response/Facebook usage). We believe Figure 1 to depict a conceptual mechanism upon which the prediction of Facebook behaviour can be effectively advanced.

\section{--- Insert Figure 1}

From a methodological standpoint, the model requires a two-phase research approach. Firstly, the features of Facebook (i.e. stimuli) from an individual's psychological needs/goal perspective need to be determined (Study 1). This will then enable the hypotheses (in relation to personality/behavioural dispositions and behavioural group prediction) to be proposed and tested on the basis of an empirically valid foundation (Study 2).

\section{STUDY ONE}

Study One required a qualitative approach to data collection in that the goal of this study was to determine the psychological features of Facebook, as perceived from the individual's standpoint. On this basis, the following research question (refer Figure 1 and the preceding sections for justification of the research question) is posed: 
RQ1: What are the psychological features of Facebook i.e. that relate to the individual's uses, needs and goal fulfilment?

\section{Method}

A random sample of 2500 email addresses was obtained from an Australian national market research firm. Potential respondents were emailed a link to an online survey which, firstly, contained one classifying question (Do you have an active Facebook account? Yes/No). Respondents were then asked to write their motivations for using Facebook (existing users) or their motivations for not using Facebook (non-users). Of these, they were asked to nominate their top three key motivations/goals. These questions were very broad and openended so that the respondent was not led (or influenced) in any way. In addition, demographic data in the form of age, gender, income and frequency of Facebook use were gathered.

The resulting sample comprised 523 respondents (representing a 21\% response rate); 337 of which had current active Facebook accounts (users) and 186 who did not have Facebook accounts (non-users). Average age of respondents was 35 years, ranging from 18 to 69 years, and the gender split was $48 \%$ male and $52 \%$ female. The median income range of respondents was $\$ 40,000$ p.a. to $\$ 60,000$ p.a. and the median frequency of Facebook usage (for the user group only) was "at least once a day" (56\%). 


\section{Analysis and Results}

Responses to the open-ended survey questions were content analysed, independently, by each of the three researchers, at which point each researcher identified the relevant themes emerging from the data. Upon completion of this task, the three researchers compared their analyses and underwent a process to reach consensus in relation to the identification and labelling of themes. As a result of this iterative process, Table 1 outlines the findings of Study One, which includes identified themes, frequency of mention and example quotes from respondents.

\section{--- Insert Table 1 ---}

As shown in Table 1, emergent themes were labelled as (1) interaction - two-way communication and proximity (not restricted by geographic boundaries); (2) self-image control - non-verbal and verbal; (3) usage volition - behavioural control; (4) risk-social and personal identity; and (5) other - demographics, resources and perceived value. The first four themes are good representations of the psychological features of Facebook that tap into the need/goal gratifications of individuals.

From a psychological viewpoint, Facebook enables two-way communication that is not restricted by geographic boundaries, thus, enabling individuals to "keep in touch" and satisfy their social goals. In addition, as Facebook communication can be asynchronous and non-visual it affords individuals a certain degree of self-image control in their communications, allowing them to control self-identity, expression and communication. Psychologically, another key aspect associated with Facebook, is the pressure (by peers and 
social groups) put on individuals to participate within the Facebook community. In this sense, the non-volitional behaviour experienced by some Facebook participants is the result of the individual seeking out social or group membership approval. Risk was also identified (particularly by the non-user group) as being a key aspect, associated with Facebook, particular in terms of openness to psychological and personal identity abuse. On this basis, Facebook was perceived as providing a platform for privacy encroachment, thus deterring individuals with a strong need for privacy. The last category, labelled as "other", comprised of motivations that were not of a psychological nature. For example, some comments were demographic in nature (i.e. age related); some comments related to resources (i.e. they didn't have to pay for Facebook (users) or they only had limited access to Internet (nonusers); other comments related to no key motivation to participate (i.e. no perceived benefit and/or just a waste of time). In summary, the findings indicate that from the individual's perspective, the psychological features of Facebook are grouped under the following four categories (1) interaction, (2) self-image control, (3) usage volition and (4) risk. These themes provide the basis for hypotheses development and testing in Study Two.

\section{STUDY TWO}

The purpose of Study 2 was to, firstly, use the findings from Study 1 (i.e. psychological features of Facebook) in order to develop context-relevant hypotheses in relation to appropriate psychological dispositions in their prediction of Facebook (non) behaviour. Secondly, in order to test these hypotheses, quantitative data were gathered via a national on-line survey. These steps are further outlined. 


\section{Hypotheses Development}

The following discussion links the psychological aspects of Facebook (i.e. findings of Study One) with relevant psychological dispositions in order to, then, present the hypotheses in relation to behavioural prediction.

Linking Interaction to Sociability: The first psychological feature of Facebook (as nominated in Study One) was labelled as "interaction". This dimension related to the individual's attraction to Facebook as a mechanism to enable two-way dialogue with friends, family, groups and organizations (within limitless geographic boundaries). This finding is supported by Oldmeadow, Quinn and Kowert (2013) who found that individuals' perceived Facebook qualities were social interaction; greater control of interaction; and ability to connect to people almost anywhere. Given that an individual's psychological goal, in relation to the usage of Facebook, is associated with the development and maintenance of social relations with others, the authors argue that sociability is a context-relevant (i.e. Facebook) psychological disposition.

Defined as the tendency to affiliate with others, in preference to being alone (Cheek \& Buss, 1981), sociability has received considerable attention in online consumer behaviour research. For example, one of the earlier studies of sociability and Internet usage found that, although Internet users do not become social through usage, they are likely to possess pre-existing sociable qualities (Nie, 2001). In addition, Amichai-Hamburger and Hayat (2011) found that Internet users' social lives were significantly enhanced through its usage, and Chan (2011) found sociability was positively related to increased email use, social 
network site use and frequency of instant messaging. In the particular context of Facebook, Grieve et al. (2013) found that social connectedness, through Facebook usage, was negatively related to anxiety and depression and, subsequently, allied with improved mental health and life satisfaction.

While the literature provides evidence that sociability is likely to be linked to Facebook usage, the power of this construct, in relation to behavioural prediction, has not been tested. Given that Facebook is an online platform for social interaction, thus, being an enabler for sociable individuals, the following hypothesis is posed:

H1: Sociability (SOCIAL) will serve as a significant discriminating factor in the prediction of group membership across Facebook users and non-users (in that, Facebook users will score significantly higher on this factor than non-users).

\section{Linking "Self-Image Control" with Shyness and Self-Disclosure:}

The second psychological feature of Facebook (as nominated in Study One) was labelled as "self-image control". This dimension related to the individual's attraction to Facebook as a more anonymous mechanism of expression, not externally-identifiable by verbal and nonverbal social cues. In this sense, individuals felt they had more control over the image they wished to portray on Facebook. This being the case, the authors argue that the two key dispositions relating to the "self-image control" feature of Facebook, resides within shyness and self-disclosure. 
While it is well documented that shyness and sociability are closely related (i.e. inverse relationship) (Mandel \& Shrauge, 1980; Pilkonis, 1977), the authors suggest that this is not the case with Facebook usage. As noted in the previous section, sociability is expected to be a key predictor for Facebook usage. Therefore, one would expect that shyness would negatively impact Facebook behaviour if an inverse relationship with sociability were to exist in this context. However, given that shyness is defined as expected social behaviour exemplified by feelings of awkwardness, discomfort, tension and inhibition in the company of strangers or acquaintances (Cheek \& Buss, 1981), the online environment may well provide a sense of "self-image control" attractive to shy individuals. Moreover, research shows this to be the case with Internet usage (Mesch, 2001; Morahan-Martin \& Schumacher, 2000; Sheldon, 2012) and, in fact, Chak and Leung (2004) found that shy individuals are more likely to be addicted to the Internet. Given the strong relationship between shyness and Internet usage, it is hypothesized that:

H2: Shyness (SHY) will serve as a significant discriminating factor in the prediction of group membership across Facebook users and non-users (in that, Facebook users will score significantly higher on this factor than non-users).

Self-disclosure is a pre-disposition to revealing information to single or multiple others pertaining about oneself (Wheeless \& Grotz, 1976; Wheeless, 1978). Self-disclosed information ranges from factual to private (or intimate) details about oneself (Attrill \& Jalil, 2011), "including personal states, dispositions, events in the past, and plans for the future" (Chen, 2012). In particular, the notion of self-disclosure is particularly relevant to marketers (Lee, Im \& Taylor, 2008). Given that social networking sites (like Facebook) rely on 
advertising as their primary source of revenue, self-disclosure behaviour enables customer information to be obtained and used in the customization of market offerings (Chen, 2012).

Self-disclosure is a multi-dimensional construct consisting of five factors; (1) intended; (2) amount; (3); positivity (4) intimacy and (5) accuracy (Wheeless \& Grotz, 1976). The "intended" dimension refers to an individual's tendency to consciously control information they self-disclose to others and this dimension is found to be particularly relevant in the online context. For example, research provides significant evidence that individuals are more willing to self-disclose in online interactions, as opposed to offline interactions (Bonebrake, 2002; Stritzke, Nguyen \& Durkin, 2004). Moreover, in terms of Facebook, individuals seek out this online environment largely for the purposes of self-disclosure.

The "amount" dimension refers to the individual's inclination towards frequency and duration of self-disclosure (Wheeless \& Grotz, 1976). Nosko, Wood and Molema (2010) explored disclosure on Facebook, and found that Facebook users disclosed approximately $25 \%$ of all possible information that could be disclosed. In addition, they found that, as age increased, disclosure decreased, and also those seeking a relationship disclosed the larger amount of highly sensitive information. However, to date, there have been few comparisons made with Facebook non-users, so it is difficult to determine whether this amount of disclosure is unique to the Facebook forum or not.

The "positivity" dimension refers to the individual's inclination to disclose and receive positive (as opposed to negative) information about themselves and others (Wheeless \& Grotz, 1976). This dimension has received little attention in the online environment, with the exception of Mazer, Murphy and Simonds (2007) who found that positive disclosure by 
teachers on Facebook led to enhanced student motivation, class climate and teacher credibility. However, based on self-appraisal theory, people tend to pay attention to their positive selves, while distancing their self-concepts from their negative selves (Markus \& Nurius, 1986). On this basis, in a relatively-public forum, such as Facebook, individuals would be more likely to self-disclose positive information, than negative information.

The "intimacy" dimension refers to the individual's tendency to openly self-disclose deep and intimate information to others (Wheeless \& Grotz, 1976). Once again, there is little research in relation to intimacy of disclosures in online environments. However, past research establishes that intimate disclosures have a reciprocal effect. For example, studies have shown that, in an online context, the more users tend to divulge about themselves, the more their online others, or multiple others, also follow suit (Attril \& Jalil, 2011; Collins \& Miller, 2011; Choi, Yoon \& Lacy, 2010). On this basis, the context of Facebook, where there is reduced Facebook verbal and non-verbal exposure, may be well suited to those wishing to express themselves on a personal basis.

The "accuracy" dimension refers to the individual's tendency to self-disclose precise information that is honest and accurate (Wheeless \& Grotz, 1976). This dimension appears to be particularly relevant in relation to the "self-image control" feature of Facebook, which enables control/manipulation of personal information. In line with self-presentation theory, De Souza and Dick (2009) found that young MySpace users' self-disclosures indicated signalling behaviour (i.e. presenting selective information about oneself to be viewed positively by others) and Attrill and Jalil (2011) found that online users only tend to reveal their superficial selves, being very wary about revealing their true selves. 
On the basis on the preceding discussion, it is proposed that the "self-image control feature" of Facebook attracts those individuals who are pre-disposed to self-disclosure (i.e. willingness, frequency) and who tend to explicitly use self-disclosure as a mechanism for self-expression (i.e. control over intimacy, accuracy and positive/negative exposure). On this basis, it is hypothesized that:

H3: The five factors of self-disclosure - (a) intended (SDINT); (b) amount (SDAMT); (c) positivity (SDPOS); (d) intimacy (SDINTIM); and (e) accuracy (SDACC) - will serve as significant discriminating factors in the prediction of group membership across Facebook users and non-users (in that, Facebook users will score significantly higher on these factors than non-users).

\section{Linking Usage Volition with Susceptibility to Interpersonal Influence:}

The third psychological feature of Facebook (as nominated in Study One) was labelled as "usage volition". This dimension related to the degree to which the individual's usage of Facebook was felt to be entirely voluntary, or whether they felt pressured by family and peers to participate. Individuals (respondents of Study One) frequently felt that they were only using Facebook because of the social pressure placed upon them to do so. In addition, other respondents (of Study One) said they felt coerced into using Facebook so they could enter competitions, not available to them in other online/offline forums. Therefore, it is argued here that an individual who succumbs to behaviour, based on social or other pressure, is an individual who is susceptible to interpersonal influence. Therefore, in relation 
to the "usage volition" dimension of Facebook, the personality disposition, susceptibility to interpersonal influence (SII) is further examined.

Susceptibility to interpersonal influence is a two dimensional construct, comprising of normative and informational dimensions. The normative dimension refers to the individual's tendency to behave in order to conform to the expectations of others; and the informational dimension refers to the individual's propensity to accept information, given by others, as being reality or make inferences based on other's behaviour (Bearden, Netemeyer \& Teel, 1989; Park \& Lessig, 1977). While it is expected that the normative dimension (i.e. conforming to the behaviour of others) of SII, would play a significant role in the volitional control over the decision to use Facebook, the same could also be said for the informational dimension. For example, Casló, Flavián and Ginalíu (2011) found that online users of travel websites, who were susceptible to informational influence, were more likely to find online advice to be useful and trustworthy. In addition, Chu and Kim (2011) found that both normative and informational interpersonal influence was an antecedent to online word-of-mouth on social networking sites. On this basis, the following hypothesis is presented:

H4: The two factors of susceptibility to interpersonal influence - (a) normative (SIINORM); and (b) informational (SIINFORM) - will serve as significant discriminating factors in the prediction of group membership across Facebook users and non-users (in that, Facebook users will score significantly higher on these factors than non-users). 


\section{Linking Risk to Concern for Privacy:}

The final psychological dimension of Facebook (refer Study One) centred on the notion of "risk", in particular, the risk of exposure to social and personal identity abuse. In fact, several studies have linked the existence of scams and fraud (Langender \& Shrimp, 2001), identity theft (Chakraborty, Vishuk \& Rao, 2013), cyberbullying and online sexual exploitation (Bryce \& Klang, 2009), and the accumulation of confidential information (Acquisti \& Gross, 2006; Hoadley et al., 2010), to increased concern for privacy in online environments. As a result of these privacy issues, online consumers may exhibit caution when interacting with virtual environments (Buchanan et al., 2007). On this basis, it is proposed that individuals, who are generally cautious and protective of their personal information (i.e. in situations such as banking, website interaction, document disposal, etc.), are more likely to shy away from Facebook usage. Therefore, general caution is defined as the degree to which the individual exercises caution in relation to private matters, and it is hypothesized that:

H5: General caution (GENCAUT) will serve as a significant discriminating factor in the prediction of group membership across Facebook users and non-users (in that, Facebook non-users will score significantly higher on this factor than users).

\section{Hypotheses Summary:}

The preceding sections have established the link between the psychological features of Facebook (identified in Study One) and the context-relevant personality dispositions forming 
the basis for the hypotheses in Study Two. For the purposes of clarity, Figure 2 provides a graphical account of the process of hypotheses development for Study Two. The findings of Study One revealed the psychological features of Facebook (i.e. the stimuli) grouped under the following four themes i.e. interaction, self-image control, usage volition and risk (refer Figure 2). The operationalization of these themes and the development of hypotheses for Study Two is well-documented in this section. As a result, five hypotheses, postulating that sociability (SOCIAL), shyness (SHY), self disclosure (SDINT, SDAMT, SDPOS, SDINTIM AND SDACC), susceptibility to interpersonal influence (SIINORM and SIIFORM) and general caution (GENCAUT) predict Facebook behaviour, underpin Study Two (refer Figure 2). The following sections document the methodology and results, pertaining to hypotheses testing.

\section{--- Insert Figure 2}

\section{Method}

The data collection tool for Study Two was an on-line survey. This method was deemed particularly appropriate given that the study essentially examines Facebook usage. Even though our populations of interest were both users and non-users of Facebook, it was important to survey people who had access to the Internet, regardless of whether they then chose to use Facebook or not. This eliminated the possibility that the non-user respondents did not use Facebook simply because they did not have Internet access.

\section{Survey Development}


The scale items used to measure the variables of interest in this study were sourced from the literature and only those scales that had consistently produced strong psychometric properties in previous studies were chosen. Therefore, self-disclosure was measured by the five-dimensional Revised Self-Disclosure Scale of Wheeless (1978). Dimensions include four items for intended disclosure (SDINT); four items for amount of disclosure (SDAMT); four items for positivity of disclosures (SDPOS); five items for depth/intimacy of disclosures (SDINTIM); and six items for honesty/accuracy of disclosures (SDACC). Shyness was measured via the nine-item Shyness Scale (SHY) and sociability was measured via the fiveitem Sociability Scale (SOCIAL), both drawn from Cheek and Buss (1981). General caution was measured using the General Caution Scale (GENCAUT) of Buchanan, Paine, Joinson and Reips (2007) which included four items and susceptibility to interpersonal influence was measured by a two-dimensional scale from Bearden, Netemeyer and Teel (1989). The dimensions included eight items measuring normative influence (SIINORM) and four items measuring informational influence (SIINFORM). The response format for all survey items was a six-point Likert scale ranging from (1) strongly disagrees to (6) strongly agree. In addition, demographic/categorical variables included in the survey were age, gender, income, marital status, and usage frequency. All construct definitions and items appear in Table 2.

\section{Data Collection}

Data collection was conducted through the employment of a web-based market research list. The populations of interest were both users and non-users of Facebook. A random sample of 3000 respondents was generated from a consumer database of the market 
research firm and the selected sample was sent an email (including the survey link) inviting them to participate in the study. A screening question asked respondents to nominate whether they had a current active Facebook account (Yes/No), thus creating the groups of interest in this study. The first email resulted in a total of 579 complete responses. Two weeks later a second email resulted in a further 91 complete responses being received, thus resulting in a total sample of 670 , representing an overall response rate of $22 \%$. Due to the anonymous nature of the survey, non-respondents were not identifiable. Therefore, to test for non-response bias we adopted an accepted proxy method of comparing late responses ( $n=91)$ with early responders $(n=479)$ (Armstrong \& Overton, 1977) via the use of t-tests to compare means of the relevant constructs. No evidence of significant mean differences was detected between "early" and "late" responders, therefore, non-response bias in the data was deemed to be non-problematic.

\section{Sample Characteristics}

The overall sample comprised of $49 \%$ male and $51 \%$ female respondents with an age range of 18 to 85 years, and a mean age of 43.1 years. In terms of income the sample was wellrepresented across all income categories i.e. $20 \%$ (less than $\$ 20000$ pa); $21 \%$ (between $\$ 20000$ and $\$ 40000$ pa); $19 \%$ (between $\$ 40001$ and $\$ 60000$ pa); $15 \%$ (between $\$ 60001$ and $\$ 80000 \mathrm{pa}$ ) and $15 \%$ (over $\$ 80000 \mathrm{pa}$ ). In terms of marital status, 33\% of respondents were single, $55 \%$ were married or in a defacto relationship and $12 \%$ were widowed or divorced. In relation to Facebook usage, $62 \%$ were Facebook users and $38 \%$ were non-users. Of the Facebook users, $70 \%$ of respondents accessed Facebook more than once a week. 
Comparisons were then made across the user and non-user groups to determine if the characteristics of the samples differed. Comparisons were made via cross-tabulation and via means testing where appropriate. Two key differences were identified. Firstly the user group was predominantly female $(60 \%)$, while the non-user group was predominantly male (63\%). Secondly, the mean age across the groups was significantly different $(t=-6.841, p<$ .001 ) with the user group having a mean age of 40 years and the non-user group a mean age of 48.8 years. On this basis, age and gender were identified as possible covariates and flagged for investigation in the ensuing analyses.

\section{Analyses and Results}

The analytical stage of the study was undertaken via a three-phase approach. Firstly, the data were subject to preliminary analysis which included normality tests, confirmatory factor analysis, reliability analysis and tests for discriminant validity. The purpose of this stage was to determine the psychometric properties of the scales (i.e. strong factor loadings, dimensionality and reliability) and the integrity of the data via validity checks (i.e. i.e. discriminant validity). In other words, this phase represented the pre-analysis stage, prior to computing composite variables, which were then used to test the hypotheses of this study. The second phase of analysis included testing of group differences via MANCOVA. As recommended by Huberty (1984) and Montemayor (1996), this was a necessary first step toward hypotheses testing, in that MANCOVA was used to "establish the statistical significance of group differences in whole profiles of predictor variables and to reduce the number of predictors for a classification analysis (Wang and Chen, 2001, p. 323). 
The final phase of analysis provided the results associated with the hypotheses of this study. As the goal of this research was to predict behaviour in relation to Facebook usage, discriminant function analysis was the appropriate analytical tool chosen.

PHASE ONE - Preliminary Analyses: Prior to hypotheses testing, an examination of the factor structures, reliability and validity of the measured constructs was undertaken to examine the psychometric properties of the scales. Firstly, histograms of the items were visually inspected for normality and statistics relating to skewness and kurtosis computed to ensure that non-normality was not problematic. As the absolute values of the skew and kurtosis indices were not greater than 3 and 10 respectively (Antonio et al., 2007), the data was deemed normal. Principal components factor analysis with varimax rotation was then conducted on each of the constructs of interest individually ${ }^{1}$ and the results revealed that all constructs were uni-dimensional. At this point, poor loading items $(<.50)$ and cross-loading items (> .40) (Schertzer et al., 2008) were identified and this resulted in 7 items being removed from further analysis i.e. one item for SDPOS, one item for SDINTIM, one item for SDACC, two items for SHY, one item for SIINORM and one item for SIINFORM. As shown in Table 2, the remaining data produced strong factor loadings, ranging from .76 to .95 , which is in excess of the recommended level of .50 (Shi \& Wright, 2001) and all Cronbach's alphas were very strong, ranging from .83 to .97 (well in excess of the recommended level of .70).

\section{---- Insert Table 2 here -----}

\footnotetext{
${ }^{1}$ For the purposes of this study, the five factors of the self-disclosure scale and the two factors of the susceptibility to interpersonal influence scale were treated as separate constructs.
} 
Having established the dimensionality and reliability of the data, composite variables were formed via mean estimation, the means and standard deviations of which ranged from 2.39 to 4.58 (means) and 0.90 to 1.31 (standard deviations) and are shown in Table 3.

\section{---- Insert Table 3 here -----}

Given that the effect of the five individual factors for self-disclosure (i.e. SDINT, SDAMT, SDPOS, SDINTIM and SDACC) and the two individual factors for susceptibility to interpersonal influence (i.e. SIINORM and SIINFORM) on group membership was sought, it was appropriate to firstly establish discriminant validity for all the constructs prior to further analysis. Discriminant validity was tested by a procedure recommended by Fornell and Larcker (1981) whereby the shared variance (squared correlation) between construct pairs was compared to the average variance extracted (AVE) for each of the constructs. For discriminant validity to be established, all AVE estimates must be greater that the shared variance between constructs (Fornell \& Larcker, 1981). The results indicated that all AVEs were greater than all the shared variances, therefore, discriminant validity was clearly established.

PHASE TWO - Testing Group Differences: As recommended by Wang et al. (2001), the data was firstly tested for significant group differences between the Facebook "users" (Group 1) and "non-users" (Group 2). Due to the identification of age and gender as possible covariates we did this via a two-step process which included Multivariate Analysis of Variance (MANOVA) and Multivariate Analysis of Covariance (MANCOVA) recommended by Lumpkin and Dunn (1990). The purpose of the MANOVA was to establish a baseline model 
of group differences, prior to including the covariates. The results indicated significant differences across groups with Wilks Lambda $=.82(F=14.98 ; p<.01)$. The next step was to conduct a MANCOVA which accounts for the influence of the covariates (i.e. age and gender) through regression-based analysis and the subsequent testing for group differences is undertaken on the adjusted means for the criterion variables (Lumpkin and Dunn 1990). In order to do this, gender was dummy coded (categorical variable) (as recommended by Blalock, 1960) in order to effectively run the analyses. The MANCOVA produced significant results for GENDER, AGE and GROUP. This was evidenced by Wilks Lambda of .89 (F = 7.58; $p<.01)$ for GENDER, Wilks Lambda of $.71(F=27.07 ; p<.01)$ for AGE; and Wilks Lambda of $.86(F=10.17 ; p<.01)$ for GROUP. A comparison of the baseline model and the adjusted model (with covariates) showed that GROUP was significant in both cases. This indicates that the covariates do not produce a significant effect (Darden \& Rao, 1979). To further determine the suitability of the predictor variables in discriminating between groups based on Facebook usage, the estimated marginal means (i.e. adjusted for covariate effects) were examined for significant differences between groups. The findings indicated that all mean differences were significant, except in the case of SDINTIM and SDACC. On this basis, these variables (i.e. SDINTIM and SDACC) were excluded from further analyses.

PHASE THREE - Discriminant Function Analysis: Prior to conducting the discriminant analysis, the total sample $(n=670)$ was randomly split into an analysis sample $(50 \%, n=335)$ and a hold-out sample $(50 \%, n=335)$. As the total sample was comprised of $62 \%$ "users" and $38 \%$ "non-users", random allocation for the analysis and hold out samples was done individually on each group to ensure that a similar split of "users" and "non-users" was achieved in each group. This resulted in the analysis sample being comprised of 215 "users" 
and 131 "non-users", and the hold-out sample comprising of 203 "users" and 121 "nonusers". The analysis sample provided the basis for the discriminant analysis and the hold-out sample was used for the purpose of establishing predictive accuracy.

The purpose of the Discriminant Function Analysis (DFA) was to determine the direction and intensity of each predictor variable in predicting group membership. Only predictor variables showing significant group differences from the MANCOVA (i.e. SDINT, SDAMT, SDPOS, SOCIAL, SHY, SIINORM, SIINFORM and GENCAUT) were entered for simultaneous estimation into the discriminant model. The results of the discriminant analysis appear in Table 4 and show that the discriminant function is significant with the canonical correlation being .43 , Wilks Lambda $=.815$, Chi-square $(d f=8)=69.38, \mathrm{p}<.001$ and the group centroids are .37 for "users" and -.61 for "non-users".

The predictive accuracy of the discriminant function was then assessed by examining the hit ratios of the analysis sample and the hold-out sample in relation to the proportional chance criterion ( $C_{\text {Pro }}$ ) (Bodey \& Grace, 2006). Hair et al. (1998) advocate that the hit ratios of the analysis and hold-out samples need to be $25 \%$ greater than the $\mathrm{C}_{\text {Pro }}$ for predictive accuracy to be established. As the $C_{\text {Pro }}$ was calculated at .53 , then the hit-ratios of both samples needed to be greater than $66 \%$. The hit ratios were $73 \%$ for the analysis sample and $72 \%$ for the hold-out sample, thus providing evidence of substantive predictive accuracy. In both samples, the classification accuracy was higher for the "user" group (89\% analysis sample; $87 \%$ hold-out sample) as opposed to the "non-user" group (45\% analysis sample; $46 \%$ hold-out sample). 
The final step of the analysis stage was to establish which discriminant variables exhibited significant group differences and the strengths and direction of the discriminant loadings. Group differences were assessed via F-ratios and all variables (with the exception of SDINT) were significant with $p<.05$ (refer Table 4). In addition, for discriminant variables to be substantive, Hair et al. (1998) advocate that discriminant loadings must be greater than plus or minus 0.30 . As shown in Table 4, all discriminant loadings met this criterion, with the exception of SDINT and GENCAUT. On the basis of these results, H1, H2, H3 (b), H3 (c), H4 (a) and H4 (b) were supported, while H3 (a), H3 (d), H3 (e) and H5 were not supported.

\section{---- Insert Table 4 here -----}

\section{DISCUSSION}

Through the examination of the psychological features of Facebook, as a starting point, the goal of this research was to (1) determine the context-relevant psychological dispositions associated with Facebook usage and (2) predict behaviour based on group membership (users versus non-users). The findings indicate that the context-relevant dispositional constructs that predict Facebook usage include: (1) self-disclosure i.e. the tendency for individuals to self-disclose frequently (SDAMT) and restrict their self-disclosures to those that reflect a positively (SDPOS) on them; (2) sociability (SOCIAL) i.e. the tendency to affiliate with others in preference to being alone, (3) shyness (SHY) i.e. the tendency to experience tension, concern, feelings of awkwardness, discomfort, and inhibition of normally accepted social behaviour in the presence of strangers and casual acquaintances, and (4) susceptibility to interpersonal influence i.e. the individual's tendency to conform to the 
expectations of others (SIINORM); and the individual's propensity to accept information, given by others, as being reality or make inferences based on other's behaviour (SIINFORM).

The findings in terms of sociability and shyness (which were both positive predictors of Facebook usage) reinforce the appropriateness of the research approach adopted herein. Given that sociability and shyness are argued to be two opposing personality traits (Mandel \& Shrauge, 1980), it could be expected that one would be a positive predictor and one would be a negative predictor in any given context. However, making such an assumption ignores the possibility that contexts can accommodate multiple needs/goals and, thus, serve different individuals in different ways. For example, our findings suggest that social people are drawn to Facebook because it fulfils their need to engage in two-way communication with multiple audiences. On the other hand, shy people are also drawn to Facebook because it provides them with an avenue of communication that eliminates the psychological distress of communicating in person. This finding reinforces the notion that the psychological aspects of the context, as understood through individuals' needs and goals, drive the activation and identification of dispositional traits that predict contextspecific behaviour.

In relation to self-disclosure, the findings indicate that Facebook attracts individuals who like to self-disclose on a frequent basis, but who also limit their self-disclosures to those that present themselves in a positive light to others. The "self-image control" aspect of Facebook serves this type of individual well in that they have complete control over the type of information that they disclose on Facebook. In a face-to-face setting, control of information regarding oneself is not always possible, given that verbal and non-verbal cues often provide 
a more realistic impression of the individual (which includes both positive and negative aspects). In line with temporal self-appraisal theory (Wilson \& Ross, 2001), people pay more attention to their positive selves by distancing (or ignoring) their negative selves (Ross \& Wilson, 2002). In doing so, they consistently maintain a positive evaluation of their current self, which is always viewed as being better than their past self (i.e. I am better now than I was before) (Wilson et al., 2012). On this basis, it is not surprising that Facebook provides an attractive avenue for individuals who feel the need to engage in positive self-expression. In addition, it is interesting to note that the tendency for individuals to positively selfdisclose, was the strongest predictor of Facebook usage within the discriminant model of this study.

The findings, in relation to susceptibility to interpersonal influence, produced somewhat surprising results. While both SII dimensions were significant, it was the informational dimension that was a stronger predictor of Facebook usage, over the normative dimension. Recall that the normative dimension refers to the individual's tendency to conform to the expectations of others, while the informational dimension refers to the individual's tendency to accept information from others as evidence of reality. Given that the qualitative findings in Study 1 suggested that individuals engaged in non-volitional use of Facebook largely due to the pressure they perceived from friends and family, it was expected that the normative dimension would be the stronger predictor of Facebook usage. However, for marketers, having access to individuals who are motivated to use Facebook based on their susceptibility to informational influence, is good news. As "informational behaviours include discussing products with friend and relatives, asking advice of others prior to making a purchase, avoiding a purchase because others said it was unsatisfactory and having asked an 
"expert" about a contemplated purchase" (Bearden et al., 1989, p. 478), marketers have the opportunity to utilize Facebook for the purposes of providing and promoting product information to a receptive, rather than hostile, audience.

\section{Practical Implications}

What is gleaned from the findings of this study is that Facebook users (1) like to interact with people, groups and organizations, (2) like to talk a lot about themselves, (3) use Facebook as a mechanism to portray positive (and maybe somewhat unrealistic) images of themselves to others, (4) tend to conform to social norms (5) are very trusting of the information/advice they seek out from others, and (6) feel comfortable in communicating within an environment where physical proximity with others is not required. From an advertising/marketing practitioner perspective, these findings have implications in relation to marketing communications' strategy.

In general, the findings suggest that advertisers, in their development and execution of communication strategy, could benefit from tailoring their messages to suit, not only their specified target market, but also the characteristics of individuals who seek goal attainment through the chosen advertising medium. It is not suggested that advertisers lose sight of their target, but by integrating additional tactics that may bide well with the medium's users, in general, may result in increased market share or even entry into new markets. For example, Facebook advertisers should embrace interactive communications that involve multiple dialogues between themselves, communities and individuals, thus accommodating the need for social interaction of Facebook users. In addition, given that Facebook users 
strongly promote their positive selves through this medium, we suggest that positivelyframed (as opposed to negatively-framed) advertising messages may prove to be significantly more effective with this group. This notion is proposed on the basis that Facebook users shy away from viewing themselves in negative circumstances. Emotional and transformational advertising appeals should also be used to tap into Facebook users' need for self-image enhancement and portrayal to others. Finally, the use of "expert" sources and testimonials in advertising is strongly recommended. This particularly taps into Facebook users' tendency to be highly influenced by (and not critical of) the opinions and advice of others.

\section{Theoretical Implications and Future Research}

Traditionally, personality traits/dispositions they have been modelled as antecedents to attitudes and behaviours (Kwak, Jaju \& Larsen, 2006; Licata, Mowen, Harris \& Brown, 2003), based on the notion of their enduring qualities. In more recent times, however, situational/contextual aspects have been acknowledged as important contributors to the personality/behaviour relationship through their significant moderating influence (Michel \& Shoda, 1995). In this study, we adopt the view that it is the situation/context that should assume the antecedent role in relation to personality and behaviour. In support of this, we use stimulus-organism-response theory to frame our study.

Given the myriad of personality traits/dispositions that define individuals as being individual, it is illogical to assume that this intricate psychological network is consistently activated in order to direct behaviour. Rather, the situation/context provides the stimuli to 
psychological trait (i.e. organism) arousal, thus, determining which aspects of a person's psychological make-up are activated (or remain dormant) to induce a behavioural response.

In using this approach, psychological traits or dispositions are not viewed as representing the key antecedent states in predicting behaviour, as previous research has assumed (e.g., Kwak, Jaju \& Larsen, 2006; Licata, Mowen, Harris \& Brown, 2003). Rather, psychological traits/dispositions serve as mediating influences between the stimuli (in this case, Facebook) and the response (in this case, Facebook (non) usage) and are dependent on the stimuli for trait/disposition activation. This would explain why psychological traits have, in the past, produced poor results in explaining behaviour (Mischel \& Peak, 1982). As demonstrated in this study, as the behavioural relevance of traits/dispositions in any given context is solely dependent of the psychological features of the stimuli, then it is not surprising that previous research, which has arbitrarily assigned traits/dispositions to behaviours, has failed to find a strong predictive behavioural link. Therefore, from a theoretical standpoint, the examination of traits/dispositions must follow an approach that, firstly, examines the stimuli (based on its psychological features) in order to identify the context-relevant traits/dispositions that will ultimately predict behaviour.

No doubt future research will lead to the refinement of this approach. However, it is advocated here that much can be gained, with any behavioural research, if the process begins with a thorough analysis, of the research context, from a needs/goal perspective of the behavioural participant. As a result, hypotheses are then developed on empirical evidence that justifies the selection of test variables (i.e. psychological dispositions), rather than upon arbitrary selection, substantiated on the basis of previous research findings, 
often drawn from varying situations/contexts. From a marketing perspective, much can be gained by a more specific investigating of different communication channels, regardless of whether they reside within the same communication category. For example, just because websites, Twitter and Facebook all operate within an online environment, does not mean that all will meet the psychological needs and goals of individuals in the same manner. On this basis, the authors warn against generalizing behavioural predictions across broad marketing domains (i.e. media contexts, service contexts etc.), but alternatively urge that future research examine each context on its own merit. As a result, it is suggested that future research opportunities are only limited by the number of examinable contexts within which human behaviour occurs.

\section{LIMITATIONS}

Firstly, the use of survey research does not come without its associated limitations given that the validity of the results is dependent upon the respondent's ability to articulate their attitudes and feelings appropriately within the constraints of the survey questions. However, in adopting the use of multiple item measures which, through the analyses, demonstrate the strength of their psychometric properties, and by undertaking tests for validity and bias, the integrity of the data from this survey collection is established. Secondly, the advantages of conducting quantitative research involving large sample sizes, reside within the generalizability of the results across geographic and/or contextual boundaries. From a geographic perspective, the normative features of Facebook are relatively standardized across the globe, with country-customization mainly occurring at the linguistic level. However, the central tenet of this paper is that the psychological, rather 
than normative, features of Facebook ultimately dictate dispositional arousal and, subsequent, behavioural prediction. This being the case, cultural nuances may well emerge when studying the psychological features of Facebook as perceived by individuals of different cultural backgrounds. In addition, the key purpose of this paper was to glean a contextually-specific understanding of one social media domain i.e. Facebook. On this basis, the findings of this study cannot be generalized (or were never intended to be generalized) beyond Australia or beyond the realms of Facebook usage (i.e. not even to other social media forums which are characterized by their own psychological features). However, in generalizable terms, the research framework conceptualized herein (refer Figures 1 and 2) can be effectively used to guide future research across many cultures and unlimited marketing contexts. On this basis, a significant contribution, to the literature, is made. 


\section{REFERENCES}

Acquisti, A. and Gross, R. (2006), Imagined Communities: Awareness, Information Sharing, and Privacy on the Facebook, Springer, Berlin Heidelberg.

Alexa. (2013), Top 500 Global Sites, Retrieved $24^{\text {th }}$ June 2013, from http://www.alexa.com/ topsites/global.

Amichai-Hamburger, Y., Wainapel, G. and Fox, S. (2002). "On the internet no one knows I'm an introvert: extroversion, neuroticism, and internet interaction", CyberPsychology \& Behaviour - The Impact of the Internet, Multimedia and Virtual Reality on Behaviour and Society, Vol. 5, pp. 125-128.

Andreason, A.R. (1965), "Attitudes and consumer behaviour: A decision model”, In L. Preston (Ed.), New Research in Marketing, Institute of Business and Economics Research, University of California, Berkley, CA.

Antonio, K.W.L., Yam, R.C.M. and Tang, E. (2007), "The impacts of product modularity on competitive capabilities and performance: An empirical study", International Journal of Production Economics, Vol. 105, pp. 1-20.

Armstrong, J. S. and Overton, T.S. (1977), "Estimating nonresponse bias in mail surveys", Journal of Marketing Research, Vol. 14, pp. 396-402.

Attrill, A. and Jalil, R. (2011), "Revealing only the superficial me: Exploring categorical selfdisclosure online", Computers in Human Behaviour, Vol. 27, pp. 1634-1642.

Ball-Rokeach, S.J. and Defleur, M.L. (1976), "A dependency model of mass-media effects", Communication Research, Vol. 3, pp. 3-21.

Bearden, W. O., Netemeyer, R.G. and Teele, J.E. (1989), “Measurement of consumer susceptibility to interpersonal influence", Journal of Consumer Research, Vol. 15, 473-481. 
Bettman, J.R. (1979), An Information Processing Theory of Consumer Choice, AddisonWesley, Reading, MA.

Blalock, H. M. (1960), Social Statistics, McGraw-Hill Book Company, New York.

Blumer, J. and Katz, E. (1974), The Uses of Mass Communications, Sage Publications, Beverley Hills, CA.

Bodey, K. and Grace, D. (2006), "Segmenting service "complainers" and "non-complainers on the basis of consumer characteristics", Journal of Services Marketing, Vol. 20, pp. 178-187.

Bonebrake, K. (2002), “College students' internet use, relationship formation, and personality correlates", CyberPsychology \& Behaviour: The Impact of the Internet, Multimedia and Virtual Reality on Behaviour and Society, Vol. 5, pp. 551-557.

Bryce, J. and Klang, M. (2009), "Young people, disclosure of personal information and online privacy: Control, choice and consequences", Information Security Technical Report, Vol. 14, pp. 160-166.

Buchanan, T., Paine, C., Joinson, A. N. and Reips, U. (2007), “Development of measures of online privacy concern and protection for use on the internet", Journal of the American Society for Information Science and Technology, Vol. 58, pp. 157-165.

Casaló, L. V., Flavián, C. and Guinalíu, M. (2011), “Understanding the intention to follow the advice obtained in an online travel community", Computers in Human Behaviour, Vol. 27, pp. 622-633.

Chak, K. and Leung, L. (2004), "Shyness and locus of control as prediction of Internet addiction and Internet use", CyberPsychology \& Behaviour, Vol. 7, pp. 559-570. 
Chakraborty, R., Vishik, C. and Rao, H. R. (2013), "Privacy preserving actions of older adults on social media: Exploring the behaviour of opting out of information sharing", Decision Support Systems, Vol. 55, pp. 948-956.

Campbell, C., Ferraro, C. and Sands, S. (2014), "Segmenting consumer reactions to social network marketing", European Journal of Marketing, Vol. 48, pp. 432-452.

Chan, M. (2011), "Shyness, sociability, and the role of media synchronicity in the use of computer-mediated communication for interpersonal communication", Asian Journal of Social Psychology, Vol. 14, pp. 84-90.

Cheek, J. M. and Buss, A.H. (1981), "Shyness and sociability", Journal of Personality and Social Psychology, Vol. 41, pp. 330-339.

Chen, R. (2012), “Living a private life in public social networks: An exploration of member self-disclosure", Decision Support Systems, Vol. 55, pp. 661-668

Choi, Y. K., Yoon, S. and Lacey, H. P. (2012), “Online game characters' influence on brand trust: Self-disclosure, group membership, and product type", Journal of Business Research, Vol. 66, pp. 996-1003.

Christodoulides, G. and Michaelidou, N. (2013), "A typology of internet users based on comparative affective states: evidence from eight countries", European Journal of Marketing, Vol. 47, pp. 153-173.

Chu, S. C. and Kim, Y. (2011), "Determinants of consumer engagement in electronic word-ofmouth (eWOM) in social networking sites", International Journal of Advertising, Vol. 30, pp. 47-75.

Chui, H-C, Pant, A., Hsieh, Y-C., Lee, M., Hsioa, Y-T. and Roan, J. (2014), "Snowball to avalanche: understanding the different predictors of the intention to propagate online marketing messages", European Journal of Marketing, Vol. 48, pp. 1255-1273. 
Collins, N. and Miller, L. (1994), "Self-disclosure and liking: a meta-analytic review", Psychological Bulletin, Vol. 116, pp. 457-475.

Dabholkar, P. and Bagozzi, R.P. (2002), "An attitudinal model of technology-based selfservice: Moderating effects of consumer traits and situational factors", Journal of the Academy of Marketing Science, Vol. 30, 184-201.

Danaher, P. and Rossiter, J.R. (2011), “Comparing perceptions of marketing communication channels", European Journal of Marketing, Vol. 45, pp. 2011.

Darden, W. R. and Rao, C.P. (1979), “A linear covariate model of warranty attitudes and behaviours", Journal of Marketing Research, Vol. 16, pp. 466-477.

DeFleur, M.L. and Ball-Rokeach, S.J. (1989), Theories of Mass Communication, Longman, New York.

De Souza, Z. and Dick, G. N. (2009), "Disclosure of information by children in social networking-Not just a case of "you show me yours and l'll show you mine", International Journal of Information Management, Vol. 29, pp. 255-261.

Edwards, J.R. (1991), “Person-job fit: A conceptual integration, literature review, and methodological critique", In C.L. Cooper \& I.T. Robertson (Eds.), International Review of Industrial and Organizational Psychology: Vol. 6 (pp. 283-375). New York: Wiley.

Endler, N.S. and Hunt, J. (1969), "Generalizability of contributions from sources of variance in the S-R inventories of anxiousness", Journal of Personality, Vol. 37, pp. 1-24.

Emarketer, (2013), "Social networking reaches nearly one in four around the world", Viewed $25^{\text {th }}$ June, 2013, http://www.emarketer.com/Article/Social-Networking-ReachesNearly-One-Four-Around-World/1009976. 
Fornell, C. and Larcker, D.F. (1981), "Evaluating structural equation models with unobservable variables and measurement error", Journal of Marketing Research, Vol. 18 , pp. 39-50.

Foxall, G. (1986), “Consumer choice in behavioural perspective”, European Journal of Marketing, Vol. 20, pp. 7-18.

Grieve, R., Indian, M., Witteveen, K., Anne Tolan, G. and Marrington, J. (2013), "Face-to-face or Facebook: Can social connectedness be derived online?", Computers in Human Behaviour, Vol. 29, pp. 604-609.

Ha, H-Y., Muthaly, S.K. and Akamavi, R.K. (2010), "Alternative explanations of online repurchasing behavioural intentions: a comparison study of Korean and UK young customers", European Journal of Marketing, Vol. 44, pp. 874-904.

Hair, J. F., Anderson, R.E., Tatham, R.L. and Black, W.C. (1998), Multivariate Data Analysis, Prentice-Hall, Upper-Saddle River.

Hoadley, C. M., Xu, H., Lee, J. J. and Rosson, M. B. (2010), “Privacy as information access and illusory control: The case of the Facebook news feed privacy outcry", Electronic Commerce Research and Applications, Vol. 9, pp. 50-60.

Hollenbaugh, E. E. and Ferris, A. L. (2014), “Facebook self-disclosure: Examining the role of traits, social cohesion and motives", Computers in Human Behaviour, Vol. 30, pp. 5058.

Hoyer, W.D. and Maclnnis, D.J. (1997), Consumer Behaviour, Houghton Mifflin, Boston. Huberty, C.J. (1984), "Issues in the use and interpretation of discriminant analysis", Psychological Bulletin, Vol. 95 No. 1, pp. 156-171.

Hui, M.K., Laroche, M. and Kim, C. (1998), “A typology of consumption based on ethnic origin and media usage", European Journal of Marketing, Vol. 32, pp. 868-883. 
Jacoby, J. (2002), "Stimulus-organism-response reconsidered: An evolutionary step in modeling (consumer) behaviour", Journal of Consumer Psychology, Vol. 12, pp. 5157.

Katz, E., Blumler, J. and Gurevitch, M. (1974), “Utilization of mass communication by the individual”, In J.G. Blumler, \& E. Katz (Eds.), The Uses of Mass Communications: Current Perspectives on Gratification Research, (pp. 19-32), Sage, Beverley Hills, CA.

Kulik, C.T., Oldham, G.R. and Hackman, J.R. (1987), "Work design as an approach to personenvironment fit", Journal of Vocational Behaviour, Vol. 31, pp. 278-296.

Kwak, H., Jaju, A. and Larsen, T. (2006), "Consumer ethnocentrism offline and online: The mediating role of marketing efforts and personality traits in the United States, South Korea, and India", Journal of the Academy of Marketing Science, Vol. 34, pp. 367385.

Lagrosen, S. (2005), "Effects of the internet on the marketing communication of service companies", Journal of Services Marketing, Vol. 19, pp. 63-69.

Langenderfer, J. and Shrimp, T. A. (2001), “Consumer vulnerability to scams, swindles, and fraud: A new theory on visceral influences on persuasion", Psychology \& Marketing, Vol. 18, pp. 763-783.

Lawlor, M-A and Prothero, A. (2008), “Exploring children's understanding of television advertising - beyond the advertiser's perspective', European Journal of Marketing, Vol. 42, pp. 1203-1223.

Lee, D., Im, S. and Taylor, C. R. (2008), "Voluntary self-disclosure of information on the internet: A multimethod study of the motivations and consequences of disclosing information on blogs", Psychology and Marketing, Vol. 25, pp. 692-710. 
Licata, J.W. and Mowen, J. (2003), "On the trait antecedents and outcomes of service worker job resourcefulness: A hierarchical model approach", Journal of the Academy of Marketing Science, Vol. 31, pp. 256-271

Lumpkin, J. R. and Dunn, M.G. (1990), "Perceived risk as a factor in store choice: An examination of inherent versus handled risk", Journal of Applied Business Research, Vol. 6, pp. 104-228.

Magnusson, D. and Endler, N.S. (1977), Personality at the Crossroads: Current Issues in Interactional Psychology, Erlbaum. Hillsdale, NJ.

Mandel, N. M. and Shrauger, J. S. (1980), "The effects of self-evaluative statements on heterosocial approach in shy and non-shy males", Cognitive Therapy and Research, Vol. 4, pp. 369-381.

Markus, H. and Nurius, P. (1986), "Possible selves", American Psychologist, Vol. 41, pp. 954969.

Masur, P. K., Reinecke, L., Ziegele, M. and Quiring, O. (2014), "The interplay of intrinsic need satisfaction and Facebook specific motives in explaining addictive behaviour on Facebook", Computers in Human Behaviour, Vol. 39, pp. 376-386

Mazer, J. P., Murphy, R. E. and Simonds, C. J. (2007), "I'Il see you on "Facebook": The effects of computer-mediated teacher self-disclosure on student motivation, affective learning, and classroom climate", Communication Education, Vol. 56, pp. 1-17.

Mesch, G. S. (2001), "Social relationships and internet use among adolescents in Israel", Social Science Quarterly, Vol. 82, pp. 329-339.

Mischel, W. (1968), Personality and Assessment, Wiley, New York.

Mischel, W. and Peake, P.K. (1982), "Beyond déjà vu in the search for cross-situational consistency", Psychological Review, Vol. 89, pp. 730-755. 
Mischel, W. and Shoda, Y. (1995), “A cognitive-affective system theory of personality: Reconceptualizing situations, dispositions, dynamics, and invariance in personality structure", Psychological Review, Vol. 102, pp. 246-268.

Montemayor, E.F. (1996), "Congruence between pay policy and competitive strategy in high-performance firms", Journal of Management, Vol. 22 No. 6, pp. 889-908.

Morahan-Martin, J. and Schumacher, P. (2000), “Incidence and correlates of pathological Internet use among college students", Computers in Human Behaviour, Vol. 16, pp. 1329.

Nijssen, E., Singh, J., Sirdeshmukh, D. and Holzmüeller, H. (2003), "Investigating industry context effects in consumer-firm relationships: Preliminary results from a dispositional approach", Journal of the Academy of Marketing Science, Vol. 31, pp. 46-60.

Oldmeadow, J. A., Quinn, S. and Kowert, R. (2013), “Attachment style, social skills, and Facebook use amongst adults", Computers in Human Behaviour, Vol. 29, pp. 11421149.

Newcomb, T.M. (1929), Consistency of Certain Extrovert-Introvert Behaviour Patterns in 51 Boys, Columbia University, Teachers College, Bureau of Publications, New York.

Nie, N. H. (2001), "Sociability, interpersonal relations, and the Internet: Reconciling conflicting findings", American Behavioural Scientist, Vol. 45, pp. 420-435.

Nosko, A., Wood, E. and Molema, S. (2010), “All about me: Disclosure in online social networking profiles: The case of FACEBOOK", Computers in Human Behaviour, Vol. 26, pp. 406-418.

Park, C. W. and Lessig, V. P. (1977), "Students and housewives: Differences in susceptibility to reference group influence", Journal of Consumer Research, Vol. 4, pp. 102-110. 
Paul, P (1996), “Marketing on the internet", Journal of Consumer Marketing, Vol. 13, pp. 27-

39.

Pilkonis, P. A. (1977), "The behavioural consequences of shyness", Journal of Personality, Vol. 45, pp. 596-611.

Pozza, I.D (2014), "Mulichannel management gets "social”", European Journal of Marketing, Vol. 48, pp. 1274-1295.

Rapp, A., Beitelspacher, L.S., Grewal, D. and Hughes, D.E. (2013), “Understanding social media effects across seller, retailer, and consumer interactions", Journal of the Academy of Marketing Science, Vol. 41, pp. 547-566.

Ross, C., Orr, E.S., Sisic, M., Arseneault, J.M., Simmering, M.G. and Orr, R.R. (2009), "Personality and motivations associated with Facebook use", Computers in Human Behaviour, Vol. 25, pp. 578-586.

Ross, M. and Wilson, A.E. (2002), "It feels like yesterday: Self-esteem, valence of personal past experiences, and judgments of subjective distance.", Journal of Personality and Social Psychology, Vol. 82, pp. 792-803.

Ruggiero T. (2000), "Uses and gratifications theory in the $21^{\text {st }}$ Century", Mass Communication and Society, Vol. 3, pp. 3-37.

Schertzer, S.M.B., Laufer, D., Silvera, D.H. and McBride, J.B. (2008), “A cross-cultural validation of a gender role identity scale in marketing", International Marketing Review, Vol. 25, pp. 312-323.

Sheldon, P. (2012), "Profiling the non-users: Examination of life-position indicators, sensation seeking, shyness, and loneliness among users and non-users of social network sites", Computers in Human Behaviour, Vol. 28, pp. 1960-1965.

Stern, B.B. (1994), "A revised communication model for advertising: Multiple dimensions of 
the source, the message, and the recipient", Journal of Advertising, Vol. 23, pp. 5-15.

Shih, C-F. (1998), "Conceptualizing consumer experiences in cyberspace", European Journal of Marketing, Vol. 32, pp. 655-663.

Stritzke, W. G. K., Nguyen, A. and Durkin, K. (2004), "Shyness and computer-mediated communication: A self-presentation theory perspective", Media Psychology, Vol. 6, pp. 1-22.

Vance, A. (2012), "Facebook: The making of 1 billion users", Business Week, 1. Retrieved $24^{\text {th }}$ June, 2013, from, http://www.businessweek.com/articles/2012-10-04/facebook-themaking-of-1-billion-users.

Vernon, P.E. (1964), Personality Assessment: A Critical Survey, Wiley, New York.

Wang, C. C.L., Chan, A.K.K. and Chen, Z.X. (2001), "Segment intenders and non-Intenders in China's property market: A hybrid approach", Journal of Consumer Marketing, Vol. 18, pp. 319-331.

Wendel, S. and Dellaert, G.C. (2005), “Situation variation in consumer's media channel consideration", Journal of the Academy of Marketing Science, Vol. 33, pp. 575-584.

Wheeless, L. R. (1978), “A follow-up study of the relationships among trust, disclosure, and interpersonal solidarity", Human Communication Research, Vol. 4, pp. 143-157.

Wheeless, L. R. and Grotz, J. (1976), “Conceptualization and measurement of reported selfdisclosure", Human Communication Research, Vol. 2, pp. 338-346.

Wilson, A.E. and Ross, M. (2001), “From chump to champ: People's appraisal of their earlier and present selves", Journal of Personality and Social Psychology, Vol. 80, pp. 572584. 
Wilson, A.E., Buehler, R., Lawford, H., Schmidt, C. and Yong, A.G. (2012), "Basking in projected glory: The role of subjective temporal distance in future self-appraisal", European Journal of Social Psychology, Vol. 42, pp. 342-353. 
Table 1: RESULTS STUDY ONE: Content Analysis of Contextual Characteristics

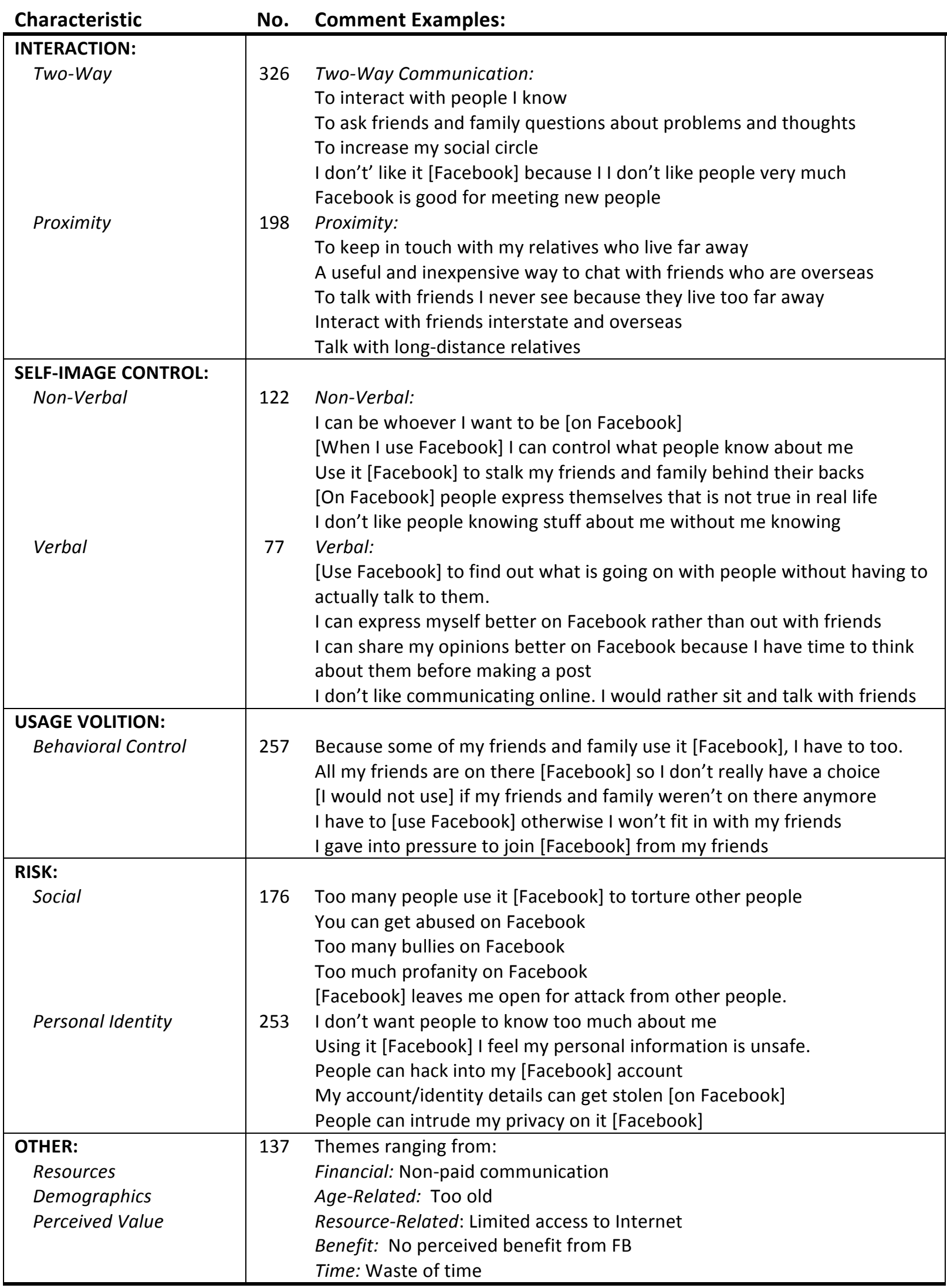


Figure 1: Theoretical/Conceptual Framework

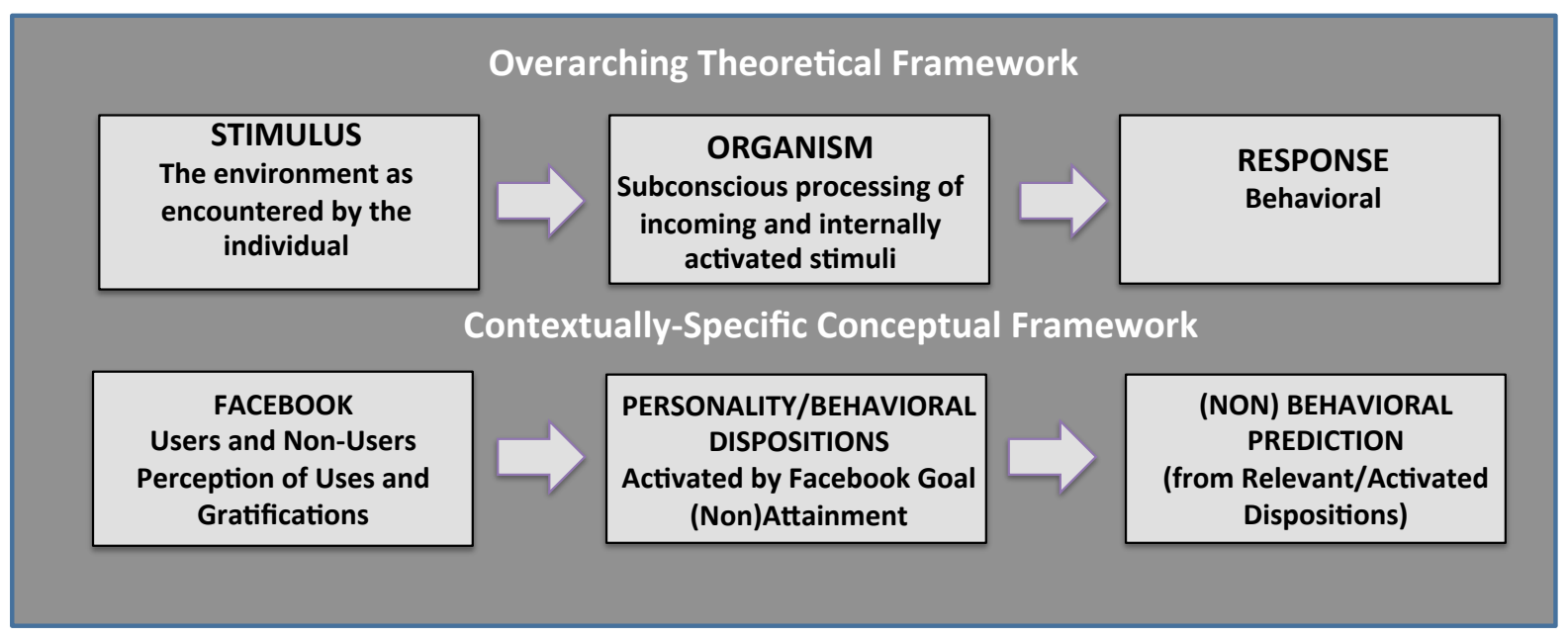


Figure 2: Framework Supporting Development of Hypotheses (Study Two)

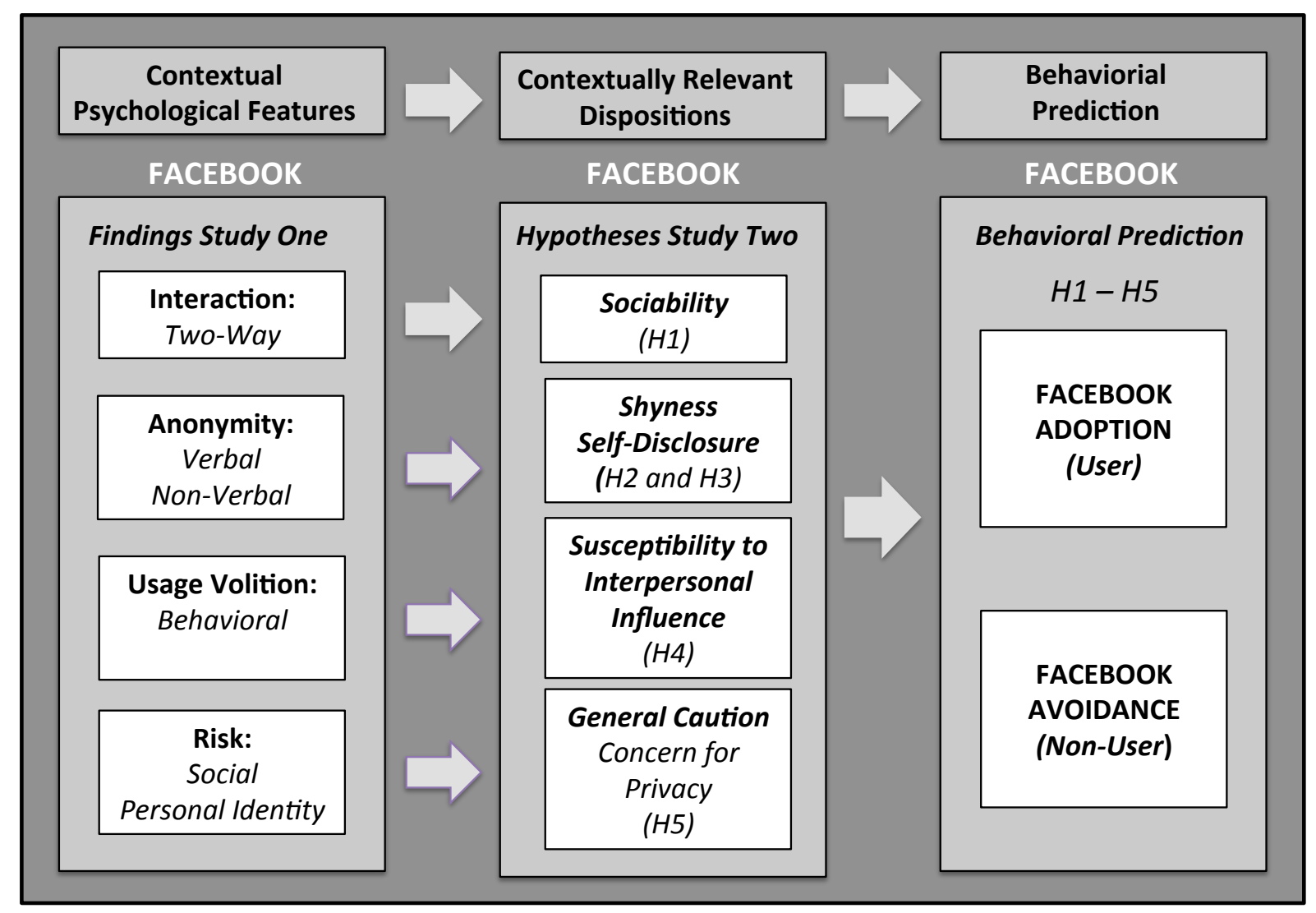

